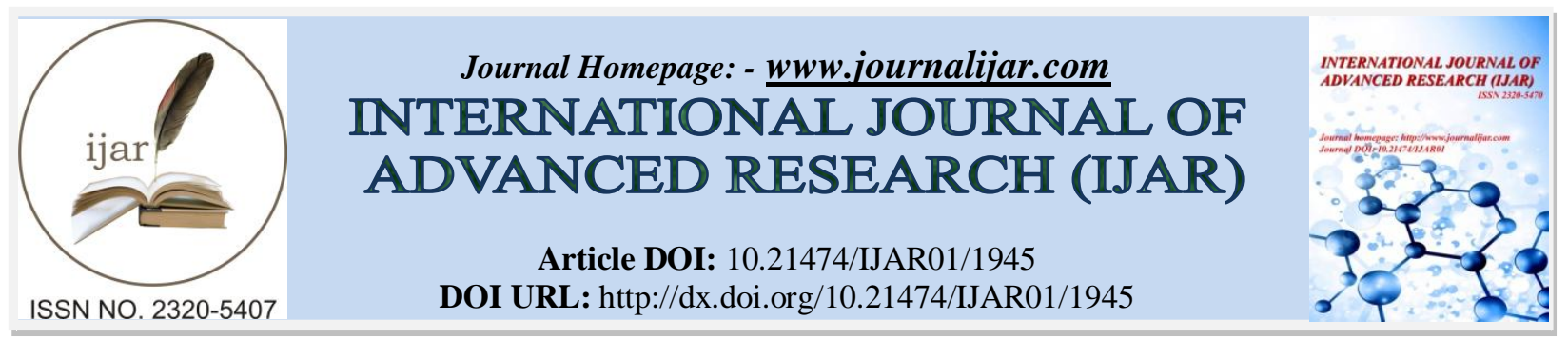

RESEARCH ARTICLE

\title{
SYNTHESIS OF COBALT, COPPER AND LEAD NANOPARTICLES USING ALLIUM SATIVUM EXTRACT.
}

Ms. B.Vijila, Dr. M. Jaya Rajan and Ms.B. T. Delma.

Department of Chemistry, Annai Velankanni College, Tholayavattam.

\section{Manuscript Info}

Manuscript History

Received: 14 August 2016

Final Accepted: 22 September 2016

Published: October 2016

Key words:-

Bio-reduction, Allium Sativum

\section{Abstract}

In this work, synthesis of Cobalt, Copper and Lead nanoparticles by bio reduction method was investigated. Allium Sativum extract was used as both reducing and capping agent. The synthesized Cobalt, Copper and Lead nanoparticle was confirmed by the change of colour after addition of extract into the Cobalt sulphate, Copper sulphate and Lead nitrate solution. The biosynthesized Cobalt, Copper and Lead nanoparticle was characterized by using UV-Visible analysis, X-ray diffraction analysis (XRD), Scanning Electron Microscopy (SEM) and Energy Dispersive X-Ray analysis (EDX).

\section{Introduction:-}

Nanotechnology is mainly concerned with synthesis of nanoparticles of variable sizes, shapes, chemical compositions and controlled dispersity and their potential use for human benefits [1]. Although chemical and physical methods [2] may successfully produce pure, well-defined nanoparticles, these are quite expensive and potentially dangerous to the environment. Biosynthesis of nanoparticles is a kind of bottom up approach where the main reaction occurring reduction/oxidation. With the antioxidant or reducing properties of plant extracts, they are usually responsible for the reduction of metal compounds into their respective nanoparticles.

The pure metals in nanoparticles form are applied in the field of diagnostics, antimicrobial agents, drug delivery, textiles (clothing), electronics, bio-sensing, food industry, paints, cosmetics, medical devices and treatment of several acute and chronic diseases malaria, hepatitis, cancer and AIDS [3].

The current investigation focused on the aqueous extract of Allium sativum used to synthesize Cobalt, Copper and Lead nanoparticles.

\section{Plant Description:-}

Garlic is a bulbous perennial herb, closely related to the onion. It has a tall, erect flowering stem that reaches 2-3 feet in height. The plant has pink or purple flowers that bloom in mid to late summer. The part used medicinally is the bulb [4]. Garlic is widely used around the world for its pungent flavour as a seasoning or condiment. From the history, it is known that garlic has been used for more than 7,000 years by humans. Originally the plant was native to central Asia [5], but it has long been used for consumption ( raw or cooked) as seasoning in many other parts of the world such as the Mediterranean region, Africa, and Europe. It has specifically been used for its medicinal purposes in ancient Egypt. [6].The garlic plant's bulb is the most commonly used part of the plant. 
Allium sativum yields allicin, an antibiotic and antifungal compound (phytoncide) discovered by Cavallito and colleagues in 1944. Fresh or crushed garlic also has enzymes, B vitamins, proteins, minerals, saponins, flavonoids, and Maillard reaction products[7].

Furthermore, a phytoalexin (allixin) was found, a nonsulfur compound with a $\gamma$-pyroneskeleton structure with antioxidant effects, antimicrobial effect, antitumor promoting effects, inhibition of a flatoxin B2 DNA binding and neurotrophic effects [8].The effects of garlic on both plant and animal models is best known for its ability to decrease the amount of lipids or free fatty acids, as well as its anti-atherogenic effects in both models.

Bionomial Name - Allium Sativum

Common Name - Garlic

Plant part taken - bulb

Family Name -Liliaceae

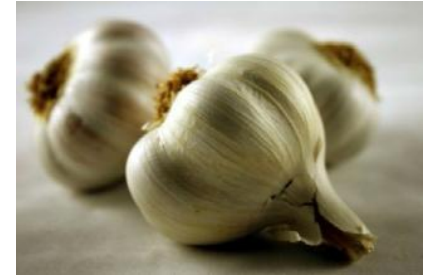

\section{Materials and Methods:-}

All reagents are in AR standards, deionised water was utilized for this process. Filtration was established by using Whatmann No.1 filter paper.

\section{Preparation of Allium Sativum extract:-}

The extracts were prepared by taking 50gms of Allium Sativum bulbs. These were thoroughly washed with deionised water and cut down into fine pieces and grinded in a mortar and pestle $(50 \mathrm{grm}$ of the sample in $500 \mathrm{ml}$ deionised water). The aqueous extract was filtered through the Whatmann No.1 filter paper and the filtrate was stored at $4^{0} \mathrm{c}$ for further experiments.

\section{Synthesis of Nanoparticles:-}

$5 \mathrm{ml}$ of Allium Sativum extract was treated to $0.1 \mathrm{M}$ of $10 \mathrm{ml}$ aqueous solution of Cobalt sulphate, Copper sulphate and Lead nitrate then stirring continued for 1 minute at room temperature. The solution was changed from white to brownish red, white to blue and white to milky white which indicates the formation of Cobalt, Copper and Lead nanoparticles.

\section{Characterization:-}

The formation of nanoparticles was confirmed by UV- Visible spectroscopy using Jasco V-550 spectrophotometer instrument. Cobalt, Copper and Lead nanoparticles was analysed with UV-Spectrometer in the range of 200 to $740 \mathrm{~nm}$. The crystalline structure of the nanoparticles were determined by X-Ray diffraction analysis using Rigaku $\mathrm{X}$-Ray diffractometer (Miniflex, UK) instrument operating at $40 \mathrm{kV}$ with $2 \mathrm{sec}$ time interval at room temperature $27^{\circ} \mathrm{C}$. Morphology and mean particle size of the Cobalt, Copper and Lead were determined by SEM analysis. The elemental composition in the reaction mixture was determined by EDX analysis.

\section{Results and Discussion:-}

UV-Vis spectroscopy analysis:-

The result obtained from UV-Visible spectroscopy analysis of the sample is presented in Fig.1.It is the most important method of analysis to detect the Surface Plasmon Resonance property of nanoparticles. The Cobalt, Copper and Lead nanoparticles formation was confirmed from the peak at 206nm, 207nm and 208nm. 


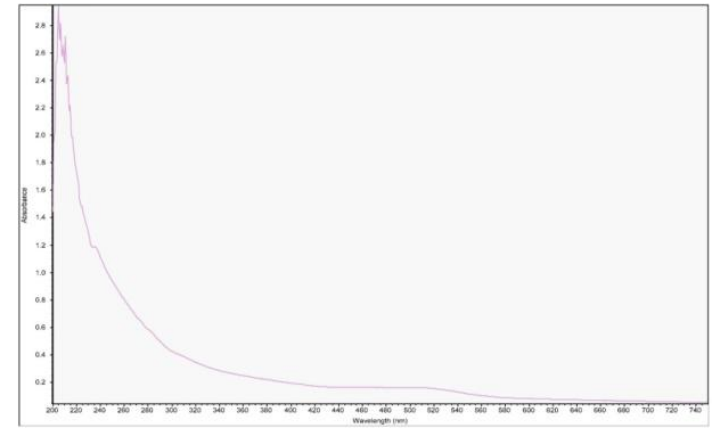

(a)

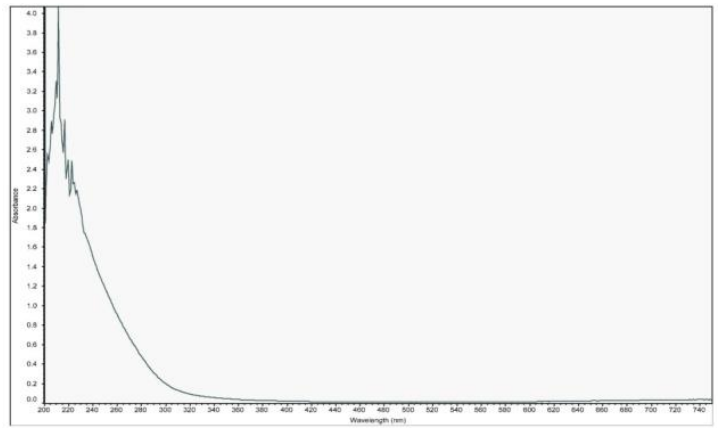

(b)

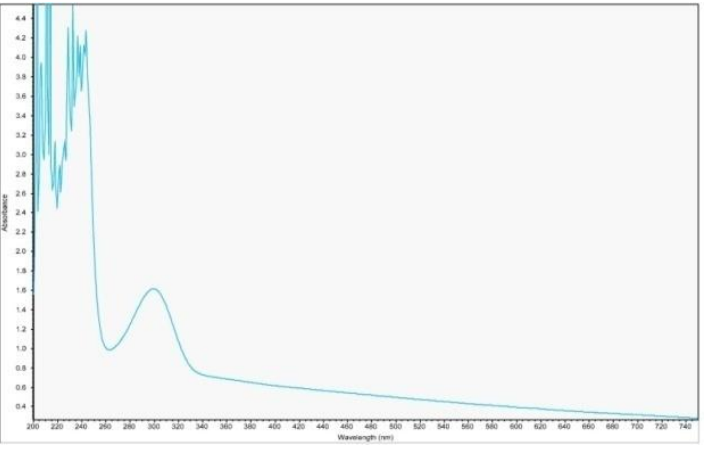

(c)

Fig. 1:- UV- Visible spectrum of (a) Cobalt (b) Copper and (c) Lead nanoparticles.

\section{XRD analysis:-}

Using XRD spectrum analysis, diffraction peaks obtained at $2 \theta$ values of $11.67^{0}, 29.13^{0}$ and $23.4^{0}$ corresponds to (111) (220) and (110) for Cobalt nanoparticles. For Copper nanoparticles, $2 \theta$ values of $63.3^{0}, 81.3^{0}$ and $25.7^{0}$ corresponds to (111) (102) and (111). For Lead nanoparticles, $2 \theta$ values of $20.1^{0}, 19.8^{0}$ and $40^{\circ}$ corresponds to (111) (100) and (111).To determine the average particle size of the nanoparticles, the Debye-Scherrer equation is used.

$$
\mathrm{D}=\mathrm{K} \lambda / \beta \cos \theta
$$

Where,

$\mathrm{D}$ is the crystalline size of NPs

$\mathrm{K}$ is the Scherrer constant

$\lambda$ is the wavelength of the X-ray

$\beta$ is the full width at half maximum of the diffraction peak

$\theta$ is the Bragg's angle.

According to Debye Scherrer equation the average particle size of Cobalt, Copper and Lead nanoparticles was found to be $2 \mathrm{~nm}, 6 \mathrm{~nm}$ and $4 \mathrm{~nm}$. 

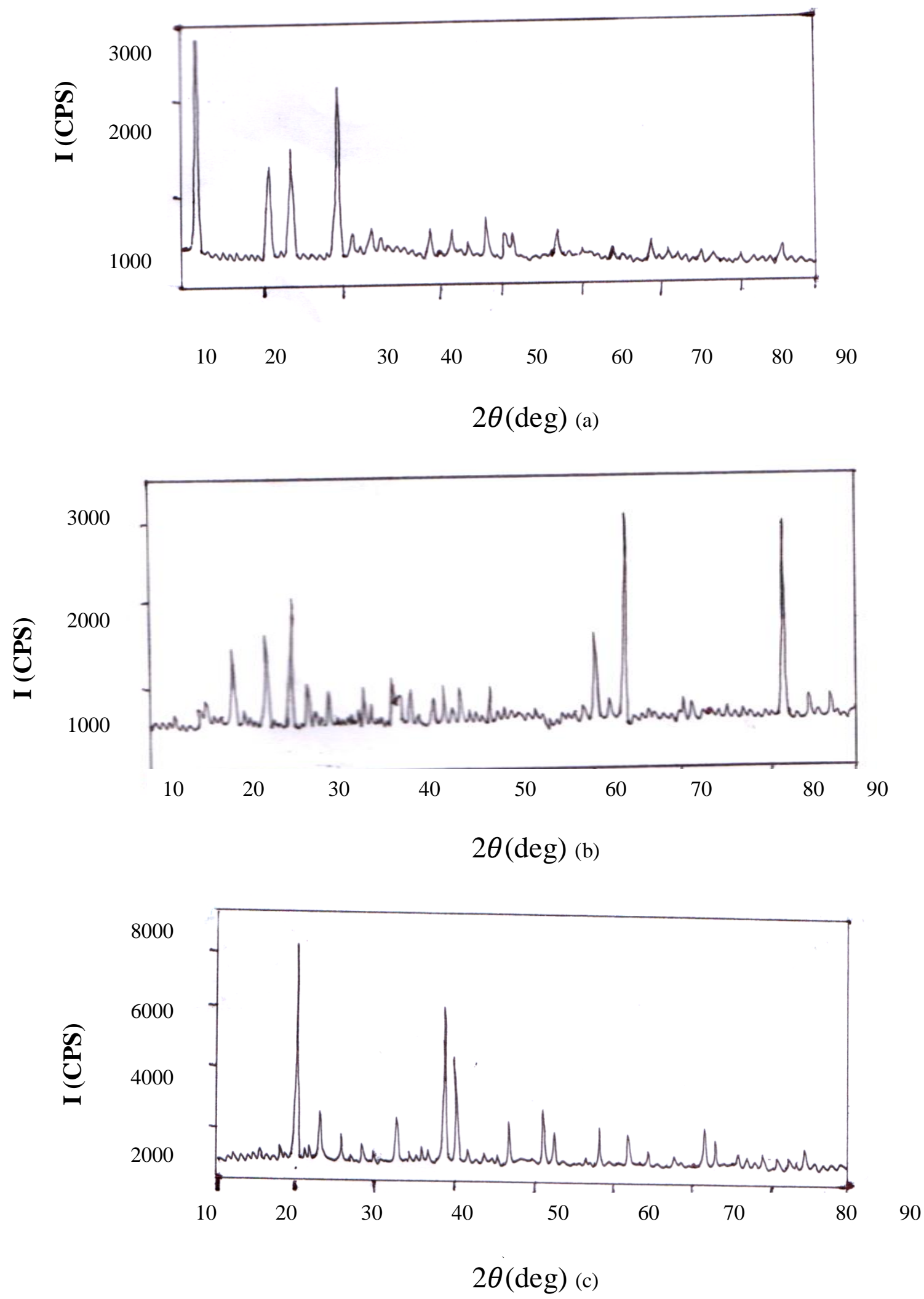

Fig. 2:- XRD analysis of (a) Cobalt (b) Copper and (c) Lead nanoparticles. 


\section{SEM analysis:-}

The surface morphology of the nanoparticles was obtained by Scanning Electron Microscopy (SEM) analysis. The Fig. 3 shows the nanoparticles synthesized by the stem extract of Allium Sativum. It was shown that spherical and relatively uniform shape of the Copper,Cobalt and Lead nanoparticles.

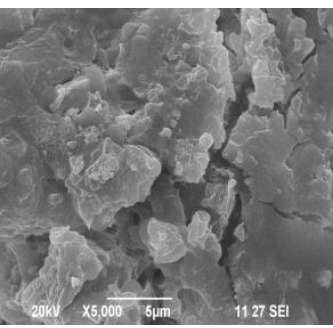

(a)

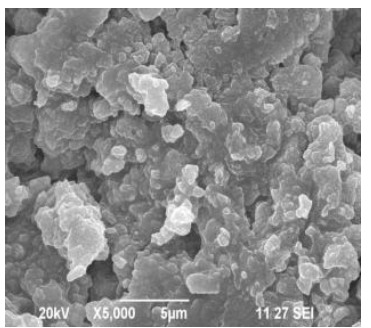

(b)

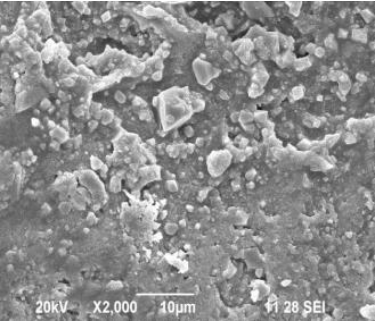

(c)

Fig 3:- SEM analysis of (a) Cobalt (b) copper and (c) Lead nanoparticles

EDX analysis data confirms the main components of the materials. The weight percentage of Cobalt, Copper and Lead nanoparticles are synthesized using Catharanthus roseus extract is 65.1\%,55.52\% and 63.0\% shown in Fig. 4

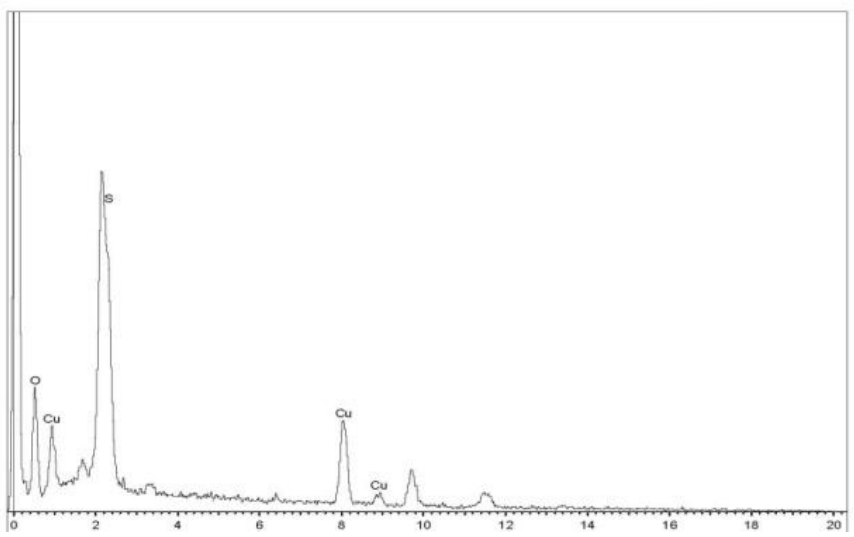

(a)

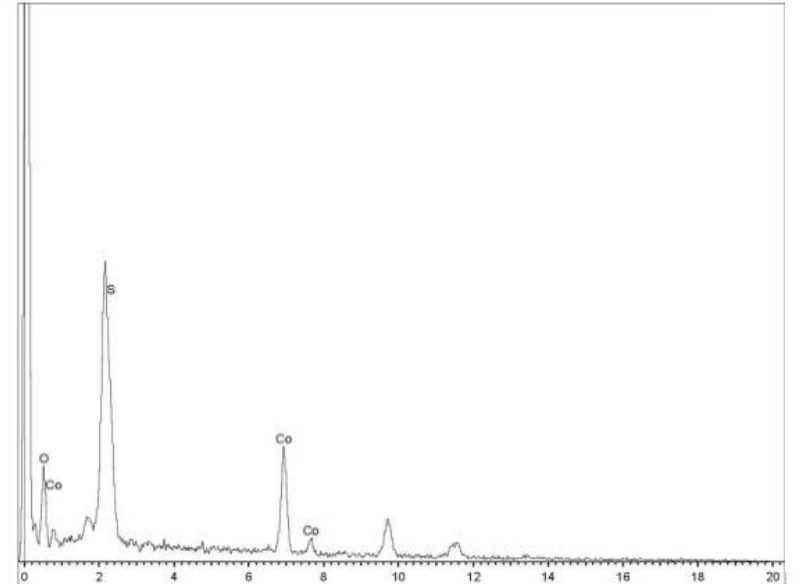

(b)

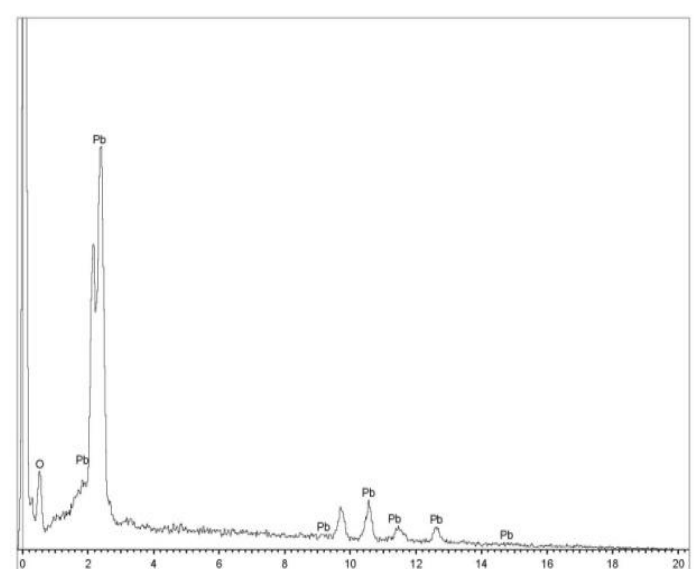

(c)

Fig.4:- EDX analysis of (a) Cobalt (b) copper and (c) Lead nanoparticles 


\section{Conclusion:-}

The Cobalt, Copper and Lead nanoparticles were successfully synthesized by using Allium Sativum extract, which provides cost effective, easy and proficient way for synthesis of nanoparticles. The synthesized Cobalt, Copper and Lead nanoparticles were analyzed using UV-spectrophotometer, SEM with EDAX and XRD. The Allium Sativum may be effectively utilized for the production of Cobalt, Copper and Lead nanoparticles with economically for many pharmaceutical applications. By UV-Visible spectrophotometer, the SPR band observed at 206nm, 207nm and $208 \mathrm{~nm}$ for Cobalt, Copper and Lead nanoparticles. XRD analysis shows the particle size of $2 \mathrm{~nm}$ for Cobalt, $6 \mathrm{~nm}$ for Copper and $4 \mathrm{~nm}$ for Lead nanoparticles. The surface morphology and main component of the material examined using SEM-EDX analysis.

\section{References:-}

1. Gervasoni J.L, "Dispersion relations for Plasmon excitations in nanostructures of different shapes and symmetries",Nucl. Instruments, Phy.Res., 2009,267,235-238.

2. Amrut Lanje S,et al., "Synthesis and Optical characterization of Copper oxide Nanoparticles",Advances in Applied Science Research 2010,1(2),36-40.

3. Roco M.C, "Nanotechnology : Convergence with Modern biology and medicine" Cur. Opin. Biotech. ", 2003, 14, 337-346.

4. Gebreselema Gebreyohanne and Mebrahtu Gebreyohannes, "Medicinal values of garlic: A review", Int J of Medicine and Medical Science, 2013, vol.5 (9), 401-408.

5. AK Khan, R Rashid, G Murtaza and A Zahra, "Gold Nanoparticles: Synthesis and Applications in Drug Delivery", Tropical Journal of Pharmaceutical Research 2014, 13 (7), 1169-1177.

6. K.V. Pavani, N. Sunil Kumar and B.B. Sangameswaran ,"Synthesis of Lead Nanoparticles by Aspergillus species", Polish Journal of Microbiology 2012, Vol. 61, No. 1, 61-63.

7. 7.S. D. Meshram, R. V. Rupnarayan, S. V. Jagtap,V. G. Mete, V. S. Sangawar," Synthesis and Characterization of Lead Oxide Nanoparticles", International Journal of Chemical and Physical Sciences 2015, ISSN:2319-660 ,IJCPS Vol. 4. 